\title{
Influences of variations in the sledgehammer trajectory and collinearity of the geophone array in an MASW survey on the shear-wave velocity profile
}

\author{
Edgar Giovanny Diaz-Segura* (1)
}

\author{
*Correspondence: \\ edgar.diaz@pucv.cl \\ Escuela de Ingeniería Civil, \\ Pontificia Universidad \\ Católica de Valparaíso, \\ Av. Brasil, 2147, 3rd Floor, \\ Valparaíso, Chile
}

\begin{abstract}
In professional activities aimed at seismic site classification, geophysical methods based on measurements of surface waves are often used to measure the shear-wave velocity (Vs), with the MASW survey being one of the most common techniques employed for this purpose. An MASW survey is characterized by an in-field configuration that requires a relatively simple setup; however, several uncertainties that arise are related to the survey execution process. Thus, surface irregularities and/or obstacles on the ground surface in conjunction with possible human-related errors can result in alterations to the MASW survey execution. Therefore, it is necessary to possess a clear understanding of the variables that can potentially produce alterations in Vs profiles. The purpose of this study was to evaluate, based on a field measurement campaign, the effect of the repeatability of the sledgehammer trajectory prior to striking the plate and the effects of variations in the collinearity of the geophone arrays on the Vs profile in consideration of various forced alterations commonly encountered in practice. The repeatability of the active source trajectory plays a significant role in the quality and reliability of Vs measurements. Likewise, altering the collinearity of the geophone array leads to reductions in the amplitude at low frequencies, thereby hindering the interpretation of the test. The recorded effects become more relevant depending on the local conditions and whether the surveyed terrain exhibits possible heterogeneity.
\end{abstract}

Keywords: Measurement uncertainties, Alterations of geophone array, Multichannel analysis of surface waves MASW, Geophysical site investigation, Shear wave velocity

\section{Introduction}

Geophysical methods based on the measurement of seismic surface waves are commonly used in professional practice to measure the shear-wave velocity (Vs), which several design codes consider as the main parameter for seismic site classification (e.g., some professional codes can be found at the following sites: IBC [1]: https://www.iccsa fe.org; EuroCode 8 [2]: https://www.cen.eu; NZS 1170.5 [3]: https://www.standards. govt.nz; and NCh 433 [4]: https://www.inn.cl). One of the most widely used methods 
employed to measure Vs is known as multichannel analysis of surface waves (MASW) [5-8].

Active-source surveying techniques such as MASW measure and analyse the propagation velocity of surface waves induced by an impulsive source (e.g., a sledgehammer). The propagation velocity of surface waves is recorded using arrays of 12 or more receivers or vertical geophones placed equidistantly in a collinear layout. Accordingly, it is possible to detect the projection of a number of waves along the axis of each array [9]. Rayleigh-type surface waves depend on the frequency in a vertically heterogeneous media, i.e., they are dispersive waves. To determine Vs profiles, inversion techniques are used for Rayleigh-type surface waves with an exploration depth of up to 30 metres under the most favourable measurement conditions $[8,10]$.

When geophysical surface wave surveying techniques are used, the uncertainties that arise are related to the measurement process, to the model employed to interpret the field data, and to the non-uniqueness of the solution $[9,11]$. An MASW survey is characterized by an in-field configuration that requires a relatively simple set-up, and instruction manuals are available that offer recommendations for the correct execution of the test $[12,13]$. However, human factors and the topographic conditions of a given site of interest can alter the survey configuration (e.g. the geophones in an MASW survey cannot always be placed to ensure their proper alignment and collinearity). Similarly, regardless of whether the recorded signals have been acquired in the same array, variations in Vs values associated with the repeatability of each test can be generated $[9,12]$.

In combination with random noise in the recorded signals, the abovementioned alterations can produce larger uncertainties in the obtained experimental dispersion curve [14-16]. Therefore, it is necessary to possess a clear understanding of the variables that can potentially produce alterations in Vs profiles. In this way, it will be possible to define an acceptable range of variation in the in situ setup for the processing of recorded signals without significant uncertainties in the Vs measurements and without considering the seismic site classification.

To assess the impacts of altering the execution of an MASW survey on the Vs profile, the present study will evaluate the effects of two factors, namely, the repeatability of the trajectories of sledgehammers weighing $4.5 \mathrm{~kg}$ and $10 \mathrm{~kg}$ prior to hitting the plate and the imperfect collinearity of the receivers, on the Vs profile.

\section{Materials and methods}

The measurements were performed in the city of Concón, Chile, in low-traffic areas with no major structures nearby. The terrain of Concón is composed mainly of a deposit of sand with moderate cementation (according to [17], and according to a standard penetration test performed at sites surrounding the study area, see Fig. 1). Based on areas for which field-testing data were available, three measurement sites were selected (shown in Fig. 1). These three measurement sites are characterized by a natural surface with low vegetation and a slope of less than $5^{\circ}$ without significant irregularities.

All measurements were collected using an ES3000 seismograph with a collinear array of 24 vertical $4.5 \mathrm{~Hz}$ electromagnetic geophones spaced every 1.5 metres. For each of the surveys, the measurements were recorded for $2 \mathrm{~s}$ with a sampling interval of $0.5 \mathrm{~ms}$ [18]. The data processing was carried out using SeisImager ${ }^{\mathrm{TM}}$ software, considering an initial 


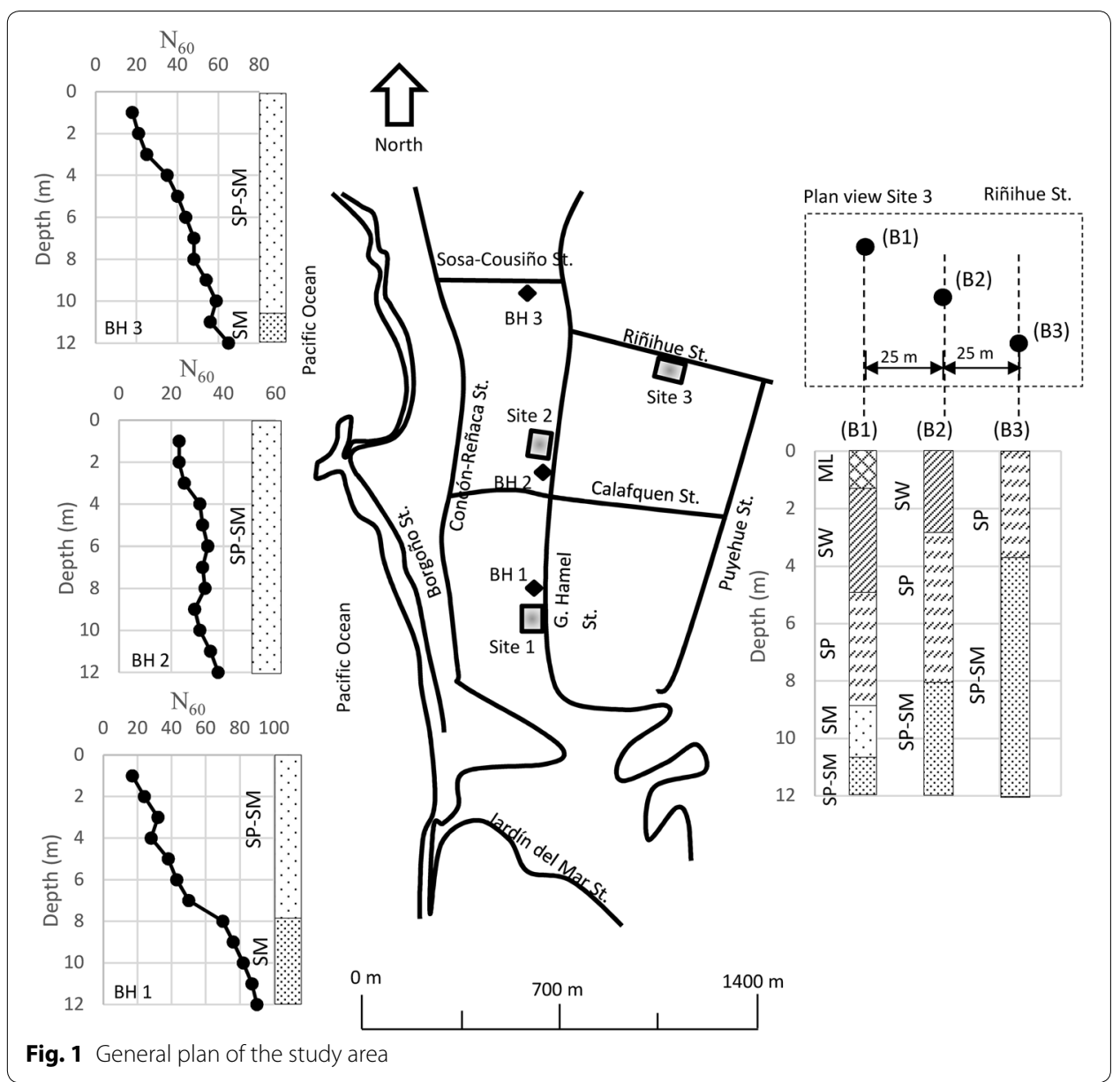

model comprising six layers with variable thicknesses based on the local search method (LSM). To reduce the number of variables that could affect the measurements and record only the surface waves generated by the impact of the sledgehammer, the surveys were conducted on weekends (very early in the morning to minimize traffic effects) under minimum wind conditions. The active source was generated manually using $4.5 \mathrm{~kg}$ and $10 \mathrm{~kg}$ sledgehammers, with 10 shots for each survey. The number of shots was chosen to ensure the generation of backup records for each measurement point. To adjust the field configuration and prevent near-field effects, a series of preliminary tests was performed, in which the offset length was successively set to $10 \%, 20 \%$ and $30 \%$ of the array length (AL). Thus, setting the offset length to $10 \%$ of the $\mathrm{AL}$ was determined to be the most appropriate option for the present study due to the conditions at the measurement site and the active source used.

\section{Effect of the repeatability of the active-source trajectory on the Vs profile}

Clearly, when using a sledgehammer as the active source, the amplitude of the signal captured by the geophones depends not only on the weight of the sledgehammer but also on the total energy of the impact on the area of the plate that the sledgehammer strikes, from which the shot originates. In principle, generating the active 
source through impacts from a heavier sledgehammer would facilitate the recording of better field measurements $[9,19]$. However, it is difficult to ensure that different shots will have exactly the same characteristics since the operator can apply a variable force, which can lead to variations in the trajectory and velocity of the sledgehammer and, accordingly, in the energy of the impact [12, 20]. As a result, with the aim of obtaining a more reliable Vs profile, it is common to carry out several shots for each array when conducting a survey at a given site. This approach allows for the stacking of field measurements and/or the possible selection of specific results if one measurement should appear particularly unusual or unreliable. Vertical stacking increases the signal-to-noise ratio by the square root of the number of shots and, hence, improves the phase velocity estimation [9]. Nevertheless, it is unclear whether field surveys can also be affected by variations in how the sledgehammer hits the plate, and it is also unclear whether these variations have any effect on the shear-wave velocity obtained from the measurements.

To date, no international standards (e.g., ASTM) have been established regarding the best way to measure the uncertainty from an active surface wave analysis. Based on previous studies, an uncertainty analysis for field measurements should be performed by estimating the coefficients of variation (COVs) for the phase velocity data and the Vs profile $[12,13]$.

On the basis of the above information, the present study analyses the influence of potential variations in the sledgehammer trajectory during each shot on the obtained Vs profile. The measurement campaign was therefore conducted using both $4.5 \mathrm{~kg}$ and $10 \mathrm{~kg}$ sledgehammers. To evaluate the influence of each sledgehammer trajectory prior to striking the plate, as well as the effect of the sledgehammer weight, the vertical position of the sledgehammer through time was recorded by filming the operator standing on an area marked with a grid [21].

To better graphically visualize the recorded sledgehammer trajectory, in Fig. 2, the trajectories of four of the 10 shots carried out with each sledgehammer are selected, and the trend line and R-squared coefficient obtained for the 10 shots for site 1 are shown. Similar results were observed for site 2. Among the trajectories of the four shots shown in this figure, those requiring the longest and shortest periods of time to generate the sledgehammer impact were selected, which allowed observing the maximum registered variation range. Figure $2 \mathrm{a}$, b show that the trajectory of the 10 kg sledgehammer exhibits less variation, i.e., better repeatability, for each shot. This is partly because the $4.5 \mathrm{~kg}$ sledgehammer weighs less and is easier for the operator to manipulate; therefore, it is easier to generate more variation in the trajectories of the different shots. However, Fig. 2c, d show that these variations do not significantly affect the Vs profiles, with COVs of less than $8.2 \%$ and $7.1 \%$ for the Vs values for the $10 \mathrm{~kg}$ and $4.5 \mathrm{~kg}$ sledgehammers, respectively. These values are below the permissible threshold of $10 \%$ for geophysical surveying and for uncertainties related to the non-uniqueness of the solution $[11,12,22]$. Thus, the repeatability of the sledgehammer trajectory during the execution of the shot has no relevant practical effect on the resulting Vs profiles. Regarding the dispersion curves shown in Fig. 2e, f, no significant variation between the two sledgehammers was observed. Figure 3 shows a slight difference in the COVs of the phase velocity, i.e., lower values are observed for 

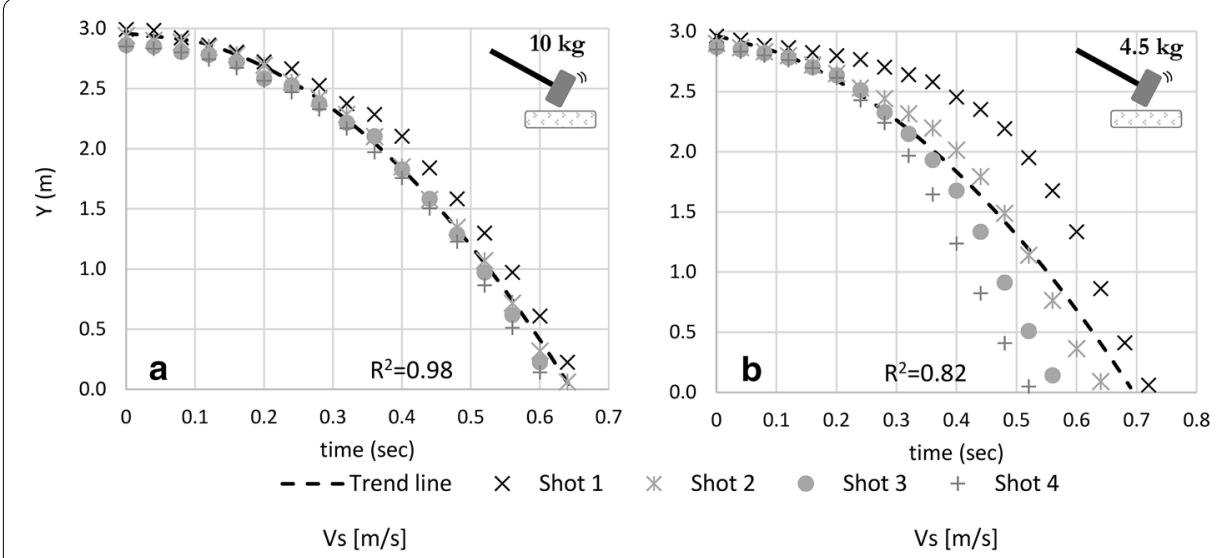

$400 \quad 500 \quad 600 \quad 700 \quad 800$

$$
\begin{gathered}
\text { Shot } 2+\text { Shot } 3+\text { Shot } 4 \\
\text { Vs }[\mathrm{m} / \mathrm{s}]
\end{gathered}
$$

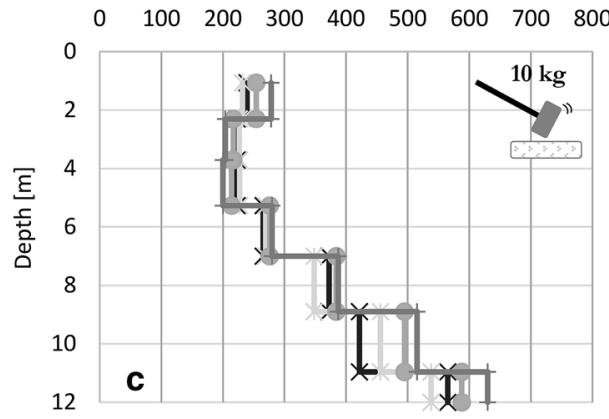

$\begin{array}{lllllllll}0 & 100 & 200 & 300 & 400 & 500 & 600 & 700 & 800\end{array}$

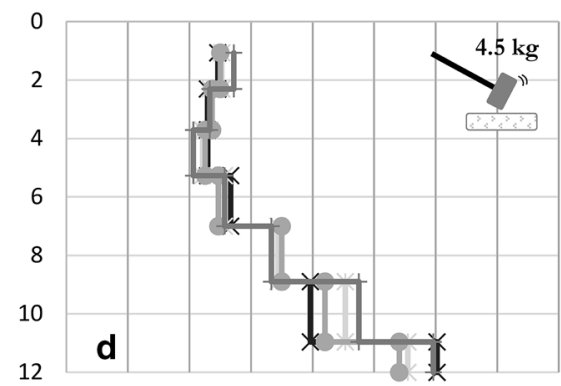

12
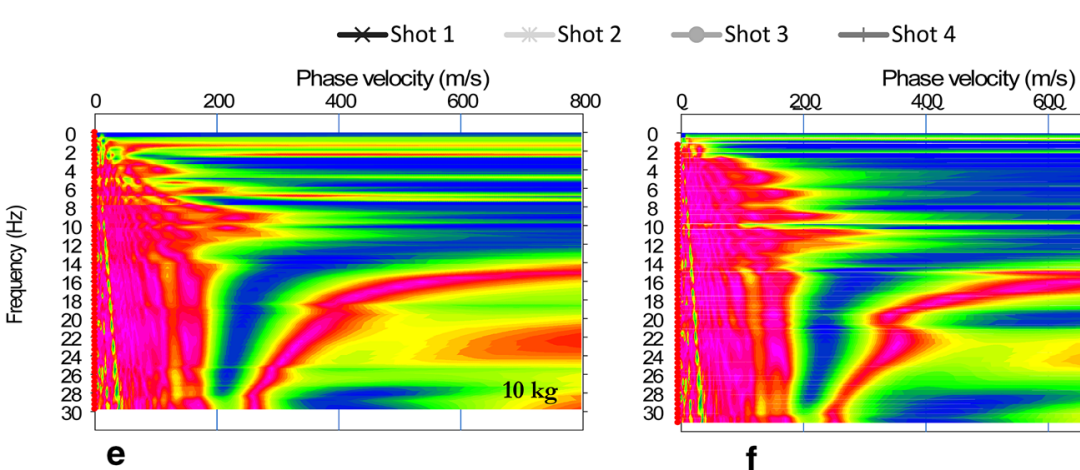

e
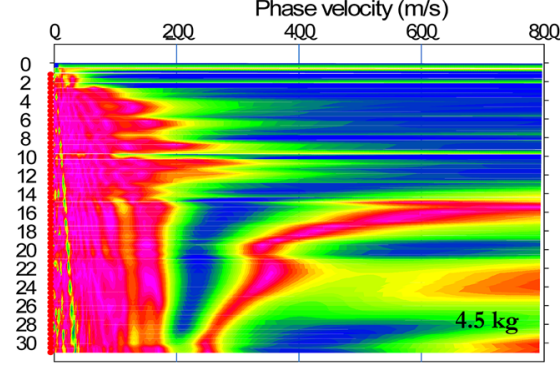

Amplitude
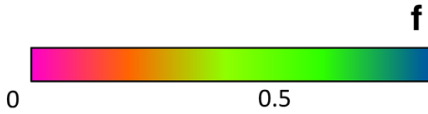

0.5

Fig. 2 Effect of the repeatability of the sledgehammer trajectory on the Vs profile: $\mathbf{a}$ and $\mathbf{b}$ trajectories of the sledgehammer; $\mathbf{c}$ and $\mathbf{d} \mathrm{V}$ s profiles; $\mathbf{e}$ and $\mathbf{f}$ dispersion diagrams

the $10 \mathrm{~kg}$ sledgehammer, although the COVs for both sledgehammers are low compared to the COVs-values that are generally recorded for active-surface wave analysis, wherein values of up to $20 \%$ are accepted $[11,12]$.

\section{Effect of altering the collinearity of the geophone array}

When performing surveys in the field, irregularities of the surface terrain that hinder the visibility of the entire array and the potential presence of thick vegetation or small obstacles must be taken into account. It is therefore possible that the in situ installation of a geophone array may not comply with the collinearity criterion. As a result, the present study aimed to analyse and evaluate the influence of altering the collinearity of an array 


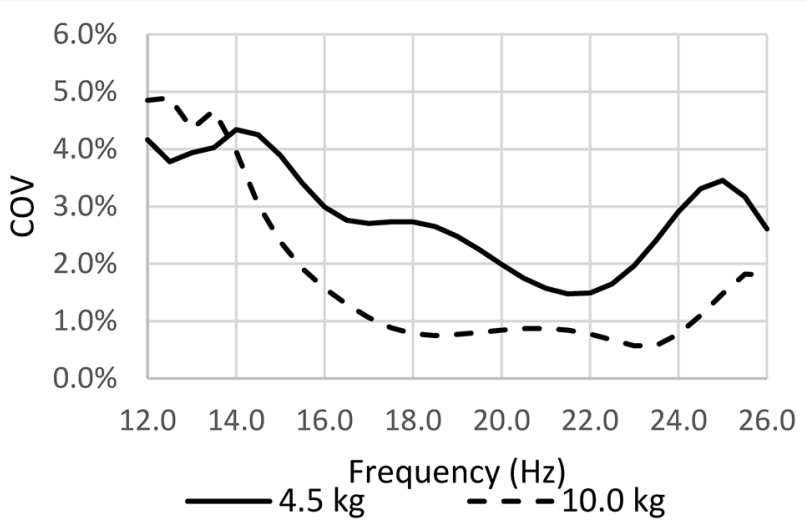

Fig. 3 Dispersion curve variability in terms of the phase velocity COVs for 10 shots carried out with $4.5 \mathrm{~kg}$ and $10 \mathrm{~kg}$ sledgehammers

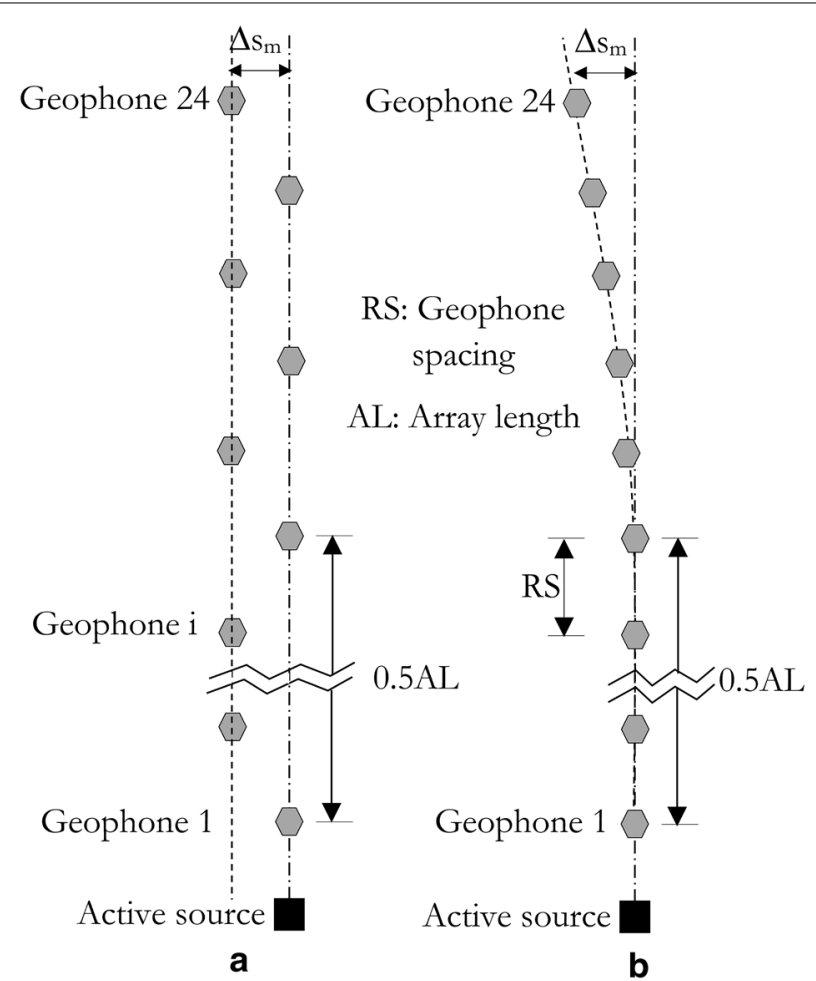

Fig. 4 Analysed cases in which the collinearity of a geophone array in a field test is altered. Case A: Some or most of the geophones are out of alignment with the original axis of the array. Case B: There is gradual variation in the positions of the receivers with respect to the original axis of the array

in a field test on the resulting Vs profile. Two possible alterations were analysed, as they are considered common in normal practice. Case A: Some or most of the geophones are out of alignment with the original axis of the array by a distance of $\Delta \mathrm{s}_{\mathrm{m}}$ (Fig. 4a). Case B: There is gradual variation in the positions of the receivers, producing a maximum deviation of $\Delta \mathrm{s}_{\mathrm{m}}$ from the original axis of the geophone array (Fig. 4b).

In total, four geophone arrays were used, three of which had installation alterations under a maximum error condition. The geophones were positioned by displacing them 


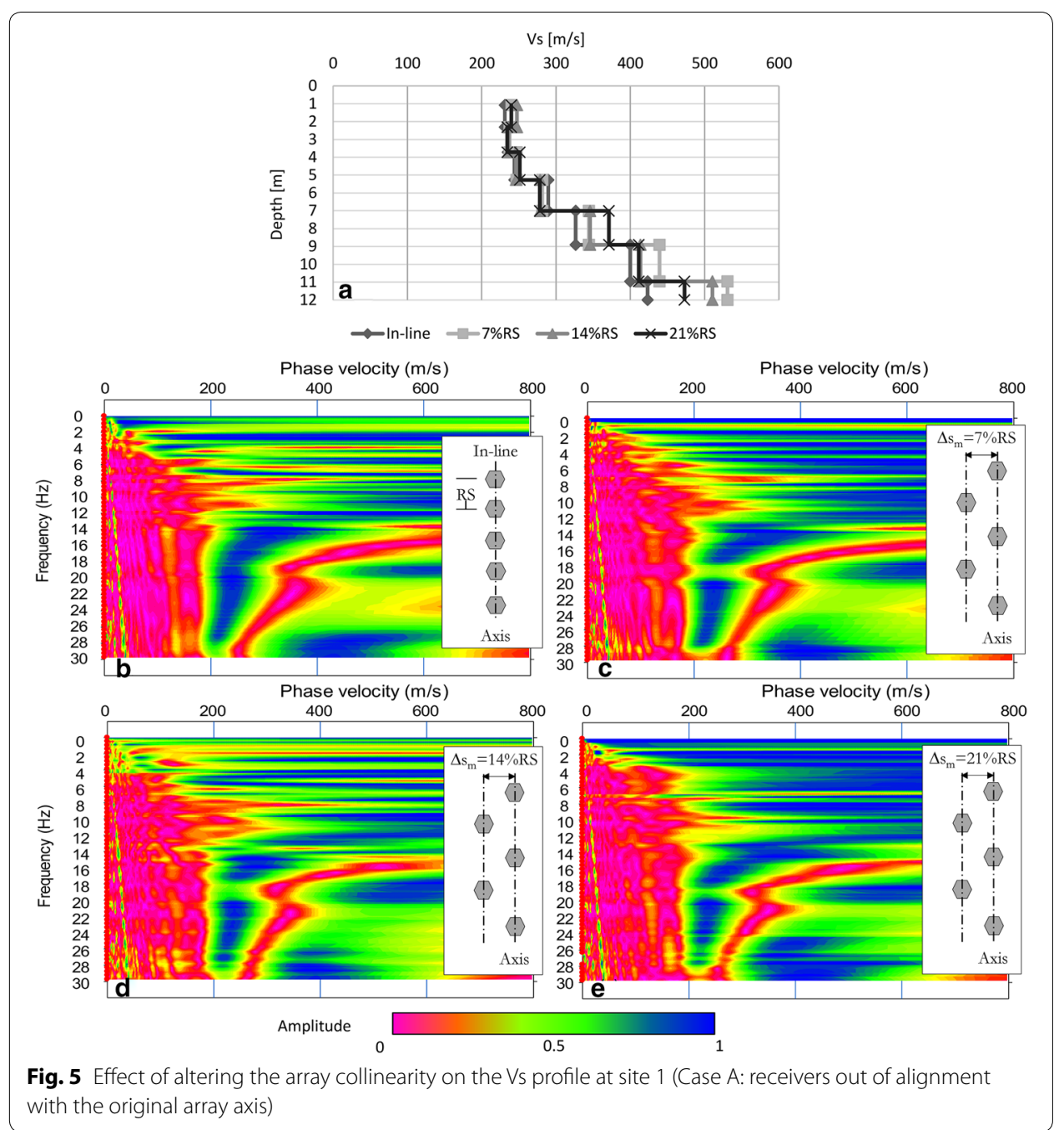

from the axis by $7 \%, 14 \%$ and $21 \%$ of the geophone spacing (RS). Figure 5 shows the Vs profiles for Case A at site 1. The term "in-line" corresponds to the Vs profile obtained with the unaltered field configuration array and the $10 \mathrm{~kg}$ sledgehammer as the active source. For Case A at site 1, the COVs recorded for the Vs and the phase velocity were less than $9.8 \%$ and $7.9 \%$, respectively. Considering that COVs of up to $20 \%$ can be accepted [12], these results demonstrate that altering the collinearity of the geophone array had little influence, even for deviations of up to $21 \%$ of the RS. Meanwhile, an alteration in the amplitude was observed in the dispersion diagrams for higher RS values, especially for some frequency ranges above $10 \mathrm{~Hz}$, which, for a practical measurement in which there is no stratigraphic information or a reference measurement with a collinear arrangement, could influence the process of interpreting the survey. Figure 6 shows the results for Case B at site 2. The responses are similar to those observed for Case A, i.e., COVs for the Vs reached up to $6.0 \%$, and COVs for the phase velocity reached up to $4.6 \%$. For both cases, the results show low variability, with COVs within an acceptable range of variation specific to the processing technique used [11]. The effects observed 


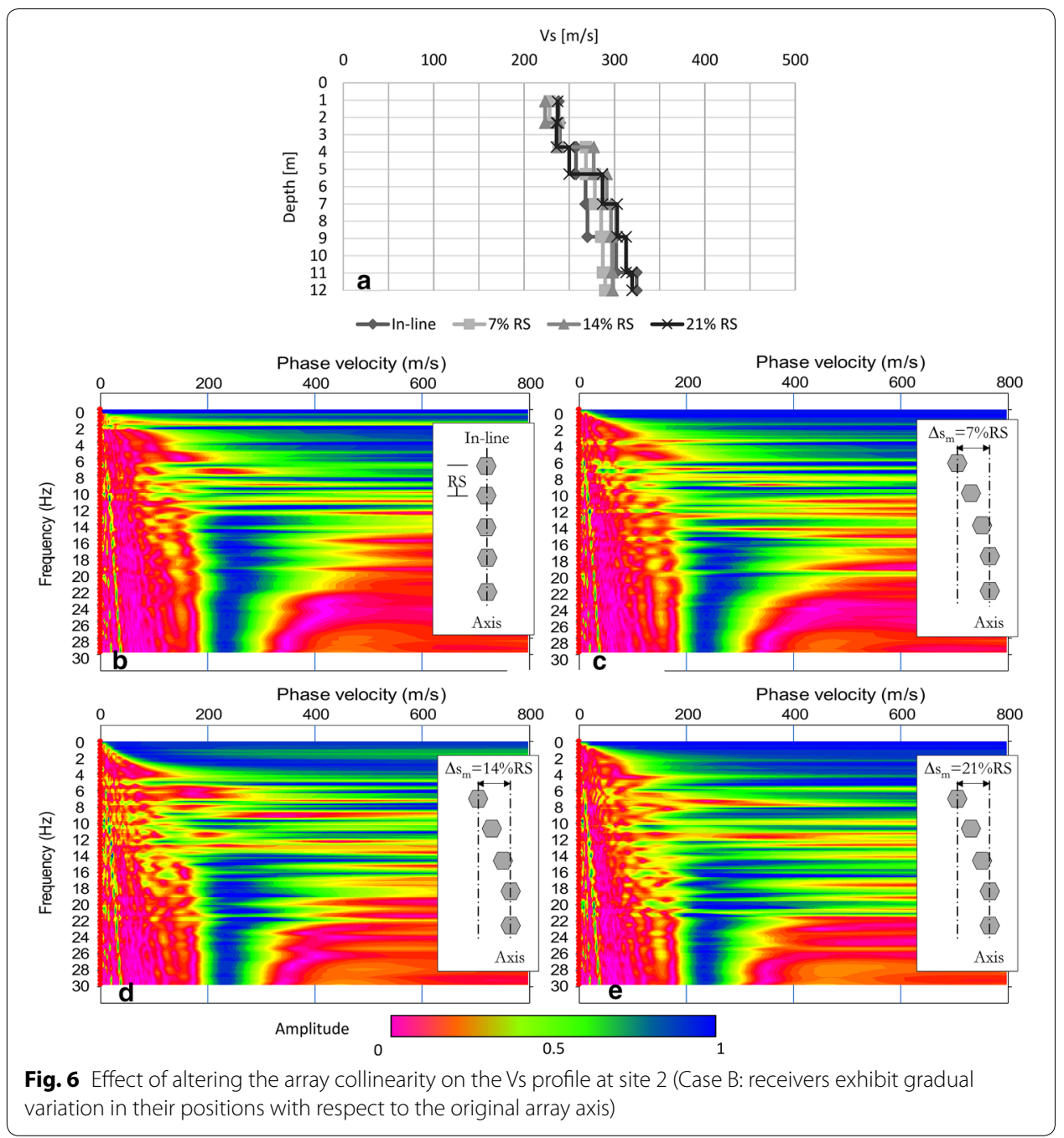

for Cases A and B were similar at both sites 1 and 2. Only one case from each study site was therefore selected.

During active surveying, the wave field is generated at the source location and is sampled along a radial line [9], and the wave travels the shortest path between the source and geophone. For the MASW method, it is therefore necessary to acquire a dataset of traces with a constant spacing along the radius. For Cases A and B, deviations in the position and azimuth of the geophones from the original axis line of up to $21 \%$ of the RS were used, so the modified travel distance did not match with the shortest path. However, this deviation did not produce a significant variation in the RS for the field array. As shown in Fig. 7, it is possible to calculate $\mathrm{RS}^{*}$ as $\sqrt{\mathrm{RS}^{2}+\Delta \mathrm{s}_{\mathrm{m}}^{2}}$. Considering that the maximum $\Delta \mathrm{s}_{\mathrm{m}}=21 \% \mathrm{RS}, \mathrm{RS}^{*}$ is equal to $1.022 \mathrm{RS}$. Therefore, considering that sites 1 and 2 (where the measurements for Cases A and B were performed) were homogenous and presented no significant lateral heterogeneity, the inversion process was not notably affected, and deviations in the array configuration did not generate significant variation in the Vs profile. However, if significant variations in the RS occurred at different points along the array, the interpretation and resolution of 


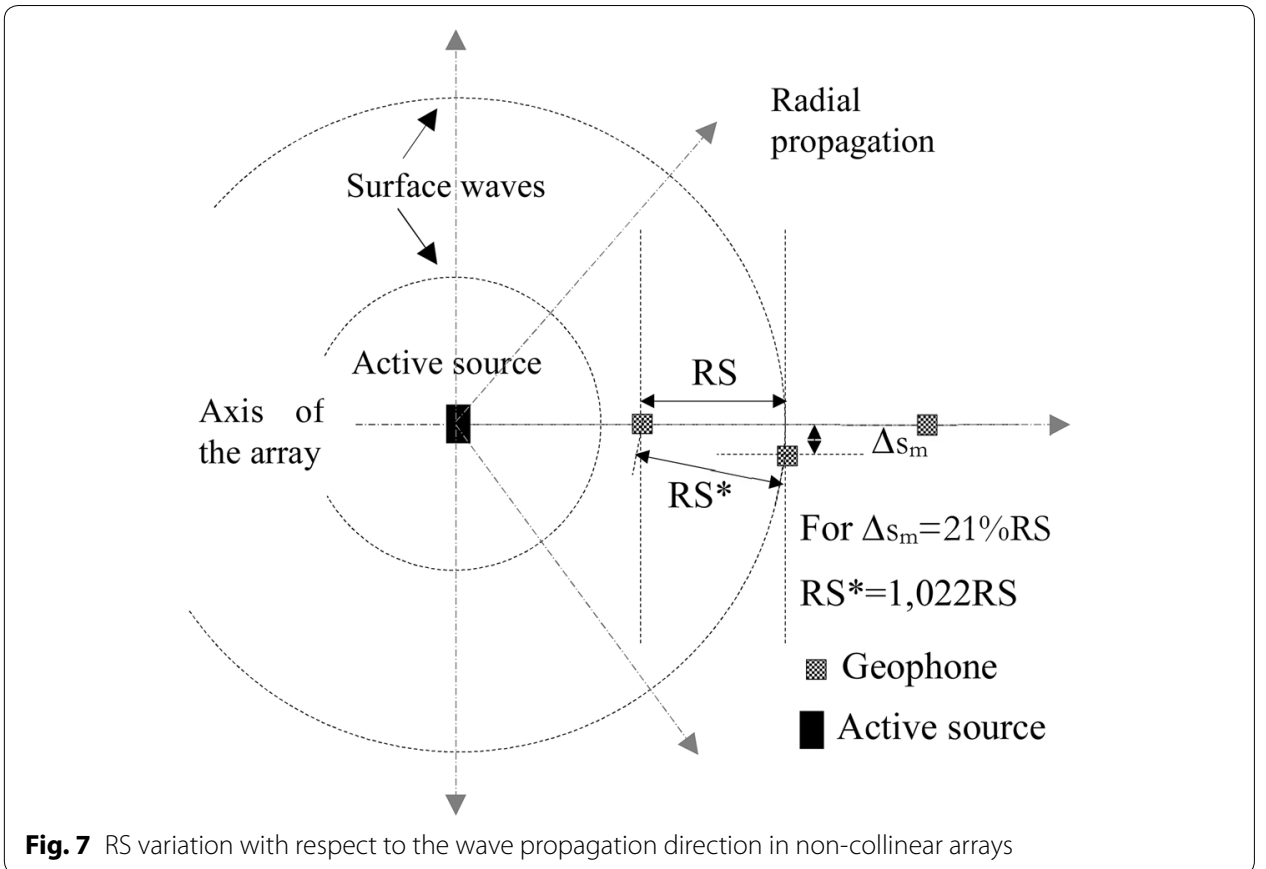

the inverse problem would require more complex methods, and the Vs profiles would be affected.

The geophones were displaced by a significant distance from the central axis of the array; hence, the dispersive characteristics of Rayleigh waves could lead to an incorrect interpretation of the obtained Vs profile, as these waves are indirectly dependent on two variables: the depth and the variable spacing between geophones along the array. Nevertheless, considering that waves propagate radially from active source shots, alterations in the field recording configuration and the difficulty in interpreting the measurements can be attributed to factors other than potential variations in the geophone spacing. In fact, when the positions of the geophones are altered, the signal is recorded in a "strip" with a width depending on the maximum deviation of the geophones from the axis. Therefore, it is likely that the recorded signal will depend on potential lateral heterogeneities in the terrain, which in turn determine the quality of the measurements and the difficulty of their interpretation [9]. To analyse the above information, measurements were performed at site 3 , which is characterized by terrain with uncontrolled soil deposition. The stratigraphy of the terrain was observed to account for the presence of lateral heterogeneities (see Fig. 1). The measurement system was installed along an axis approximately parallel to Riñihue Street. As shown in Fig. 8, in contrast to the results shown in Figs. 5 and 6, the differences in the amplitude of the dispersion diagram are more notable for the in-line array and a non-collinear array. Although surface waves can be modelled as an equivalent 1D medium, under conditions with slight lateral heterogeneity, the uncertainty in the recorded signals increases, resulting in less-reliable measured Vs values. 



Fig. 8 Differences in the dispersion diagrams for the in-line array and a non-collinear array for site 3 , which is characterized by lateral heterogeneities 


\section{Conclusions}

The active source plays a significant role in the quality and reliability of Vs measurements acquired using the MASW technique. An increased source weight commonly generates signals with a higher amplitude, mainly at lower frequencies. However, under conditions of low ambient noise and shallow exploration depths, the shot characteristics have little influence on the field recordings and do not significantly affect the Vs profiles up to a reliable measurement depth.

Altering the positions of the geophones by up to $21 \%$ of the RS with respect to the main axis of an MASW survey does not significantly impact the resulting Vs profile. However, an increased distance between the geophones with respect to the axis of the array leads to reductions in the amplitude at low frequencies, thereby hindering the interpretation of the test.

It is possible that during the setup and execution of an MASW field survey conducted to measure the Vs, the collinearity of the array can be altered due to human factors. Additionally, difficulties can arise due to the topography of the terrain. However, these alterations in the geophone array become more relevant if the terrain in question shows any heterogeneity, particularly lateral heterogeneity. Deviations in the positions of the geophones with respect to the axis of the array indirectly result in a measurement stripe along the terrain. The presence of this measurement stripe suggests that the recorded signals are altered by lateral heterogeneities, which affect the quality and interpretation of the measurements.

\section{Acknowledgements}

The author gratefully acknowledges the Pontificia Universidad Católica de Valparaíso as part of VRIEA-PUCV Project No. 39.394/2019 for part of the financial support for the present study. The author wishes to thank the engineers of the Pontificia Universidad Católica de Valparaíso, Francisco Durán, Maria José Villalobos and Jorge Oviedo, for their valuable support in conducting some of the field tests.

\section{Competing interests}

The authors declare that they have no competing interest.

Received: 6 August 2019 Accepted: 3 April 2020

Published online: 22 April 2020

\section{References}

1. ICC (2012) IBC International Building Code. International Code Council, ICC, USA

2. CEN (2004) EuroCode 8: design of structures for earthquake resistance - part 1: general rules, seismic actions and rules for buildings. European Committee for Standardization, Brussels

3. NZS (2004) Structural design actions NZS 1170.5, Part 5, Earthquake Actions New Zealand. New Zealand: Standards New Zealand

4. INN (2012) Earthquake resistant designs of buildings, NCh 433Of1996 Mod. 2012. The Chilean National Standards Institute, Chile

5. Ismail R, Ibrahim A, Hamid HA, Majid TA, Adnan A (2015) Seismic Site Classification of JKR Bridge at Sungai Sepang Using Multichannel Analysis of Surface Wave (MASW). In: Yusoff M, Hamid N, Arshad M, Arshad A, Ridzuan A, Awang H (eds) InCIEC 2015. Springer, Singapore

6. Karabulut S (2018) Soil classification for seismic site effect using MASW and ReMi methods: a case study from western Anatolia (Dikili -i̇zmir). J Appl Geophys 150:254-266

7. Moffat R, Correia N, Pastén C (2016) Comparison of mean shear wave velocity of the top $30 \mathrm{~m}$ using downhole, MASW and bender elements methods. Obras y Proyectos 20:6-15

8. Park C, Miller R, Xia J (1999) Multichannel analysis of surface waves. Geophysics 64(3):800-808

9. Foti S, Lai C, Rix G, Strobbia C (2014) Surface wave methods for near-surface site characterization. CRC Press, London

10. Xia J, Miller R, Park C (1999) Estimation of near surface shear-wave velocity by inversion of Rayleigh waves. Geophysics 64(3):691-700

11. Moss RES (2008) Quantifying measurement uncertainty of thirty-meter shear-wave velocity. Bull Seismol Soc Am 98(3):1399-1411

12. Foti S, Hollender F, Garofalo F et al (2018) Guidelines for the good practice of surface wave analysis: a product of the InterPACIFIC project. Bull Earthq Eng 16(6):2367-2420 
13. Garofalo F, Foti S, Hollender F, Bard PY, Cornou C, Cox BR, Ohrnberger M, Sicilia D, Asten M, Di Giulio G, Forbriger T, Guillier B, Hayashi K, Martin A, Matsushima S, Mercerat D, Poggi V, Yamanaka H (2016) InterPACIFIC project: comparison of invasive and non-invasive methods for seismic site characterization. Part I: intra-comparison of surface wave methods. Soil Dyn Earthq Eng 82:222-240

14. Foti S, Cox BR, Garofalo F, Hollender F, Bard PY, Cornou C, Ohrnberger M, Sicilia D (2015) Uncertainties in Vs profiles from geophysical tests and their influence on seismic ground response analyses: results from the interpacific blind test. In: 6th International Conference on Earthquake Geotechnical Engineering, Christchurch, New Zealand

15. O'Neill A (2003 Full-waveform reflectivity for modelling, inversion and appraisal of surface wave dispersion in shallow site investigations. Perth, Western Australia: University of Western Australia, 420. (Ph.D. Thesis)

16. Olafsdottir EA, Erlingsson S, Bessason B (2018) Tool for analysis of multichannel analysis of surface waves (MASW) field data and evaluation of shear wave velocity profiles of soils. Can Geotech J 55(2):217-233

17. Diaz-Segura EG (2015) Effect of MASW field configuration on the estimation of shear wave propagation velocity in a sloped terrain. Geotech Lett 5(1):21-27

18. Geometrics, 2012. Operation and reference manual for geometrics seismograph models V. 9.30. Geometrics, USA

19. Keiswetter D, Steeples D (1995) A field investigation of source parameters for the sledgehammer. Geophysics 60(4):1051-1057

20. Miller R, Pullan S, Waldner J, Haeni F (1986) Field comparison of shallow seismic sources. Geophysics 51(11):2067-2092

21. Duran F, Villalobos MJ (2015) Evaluation of the uncertainty of the measuring process of the propagation shear wave velocity. Valparaíso, Chile: Pontificia Universidad Católica de Valparaíso. (Thesis for the degree of civil engineer-in Spanish)

22. Marosi KT, Hiltunen DR (2004) Characterization of spectral analysis of surface waves shear wave velocity measurement uncertainty. J Geotech Geoenviron Eng 130(10):1034-1041

\section{Publisher's Note}

Springer Nature remains neutral with regard to jurisdictional claims in published maps and institutional affiliations.

\section{Submit your manuscript to a SpringerOpen ${ }^{\odot}$ journal and benefit from:}

- Convenient online submission

Rigorous peer review

- Open access: articles freely available online

- High visibility within the field

- Retaining the copyright to your article

Submit your next manuscript at $\mathbf{s p r i n g e r o p e n . c o m ~}$ 